\title{
Oficinas de capacitação para catadores de materiais recicláveis em Matinhos - PR: dinâmicas territoriais inclusivas, socioeconômicas e ambientais
}

\author{
Workshops for collectors of recyclable materials in Matinhos-PR, Brazil: inclusive, \\ socioeconomic and environmental territorial dynamics
}

\author{
Alexandre Dullius ${ }^{1}$ \\ Maclovia Correa da Silva ${ }^{2}$ \\ Marcia Regina Rodrigues da Silva Zago ${ }^{3}$
}

\section{Resumo}

As dinâmicas territoriais inclusivas socioeconômicas e ambientais podem ocorrer por meio de oficinas de capacitação. Essa técnica foi aplicada para os catadores de materiais recicláveis na cidade de Matinhos-PR em duas associações, em conformidade com a Política Nacional dos Resíduos Sólidos, Lei Federal n ${ }^{\circ}$ 12.305, de 2010. A gestão integrada dos Resíduos Sólidos Urbanos tem sido um desafio para os administradores públicos e para os catadores. É uma tarefa complexa e exige capacitação técnica, social, ambiental e humana. A Lei Federal no 8.666/1993 dispensa a licitação municipal para contratação de organizações de catadores de baixa renda. Porém, vulneráveis às decisões dos políticos, esses trabalhadores poderiam lidar melhor com suas tarefas e negociações se fossem constantemente capacitados por profissionais interdisciplinares. O objetivo do trabalho foi apresentar as dinâmicas territoriais de capacitação para catadores e catadoras estimuladoras de experiências inclusivas, reconhecimento e respeito. As oficinas promoveram para eles escolhas, diálogos, sentimento de pertencimento, valorização de novas oportunidades, diversidade e trocas de saberes. A metodologia, de natureza qualitativa, explorou aspectos de observação participante, de pesquisa-ação e de roda de conversa. Acredita-se que as dinâmicas territoriais dos resíduos recicláveis são desiguais, porque falta empoderamento, infraestrutura, associativismo e organização dos trabalhadores, políticas complementares com investimentos e estratégias de inclusão. No território, os catadores e as catadoras não são vistos pela população como trabalhadores organizados em associação ou cooperativa, na medida em que materiais descartados diariamente são misturados e inutilizados para a reciclagem. Consequentemente, reduzem-se as condições de ganho e de protagonismo deles.

Palavras-chaves: Oficinas. Associações de catadores de materiais recicláveis. Matinhos-PR. Dinâmicas territoriais.

\footnotetext{
Abstract

Inclusive, socioeconomic and environmental territorial dynamics can occur through workshops. This approach was applied to a group of waste collectors in the city of Matinhos-PR, Brazil, in two

1 Professor do Instituto Federal do Paraná - Campus Paranaguá. Doutorando do Programa de Pós-graduação em Tecnologia e Sociedade da UTFPR - Campus Curitiba. E-mail: alexandre.dullius@ifpr.edu.br.

${ }^{2}$ Professora do Programa de Pós-graduação em Tecnologia e Sociedade da UTFPR - Campus Curitiba. E-mail: macloviasilva@utfpr.edu.br.

${ }^{3}$ Doutoranda do Programa de Pós-graduação em Tecnologia e Sociedade da UTFPR-Campus Curitiba. Professora da Rede Municipal de Curitiba e Estadual do Paraná. E-mail: marciazagoz@gmail.com.
} 
recyclable materials associations, complying with the National Policy for Solid Waste (Federal Law n. 12.305, 2010). The management of urban solid waste has been a challenge for public managers and collectors. It is a complex task and requires technical, social, environmental and human training. The Federal Law 8.666/1993 dismiss municipal bidding for hiring low-income waste-collector organizations. However, the waste collectors are vulnerable to the decisions of politicians, which creates difficulties. We argue that if they were constantly trained by interdisciplinary professionals, they could better handle their tasks and negotiations. The objective of this paper was to present the territorial dynamics of workshops that stimulate inclusive experiences, self-recognition and respect. The workshops promoted choices, dialogues, a sense of belonging, appreciation of new opportunities, diversity, and exchange of knowledge for them. The qualitative methodology explored aspects of participant observation, case study and conversation circle. We believe that the territorial dynamics of recyclable waste are unequal because it lacks worker empowerment, infrastructure, associativism and organization, and complementary policies with investments and inclusion strategies. In territory, waste collectors are not seen by the population as workers organized in association or cooperative, as daily waste materials are mixed and rendered unusable for recycling. Consequently, their gain and protagonism conditions are reduced.

Keywords: Workshops. Recyclable waste material collector's association. Matinhos-PR. Territorial dynamics.

\section{Introdução}

Os debates são amplos quando se estudam as dinâmicas territoriais, suas relações culturais, sociais, econômicas e ambientais. Pode-se dizer que existe um consenso entre diferentes pesquisadores como Leme (2015), Vieira (2003), Sachs (2004) referente às estratégias de desenvolvimento adotadas pelos países e a progressiva acentuação das desigualdades sociais. Ao longo do século $\mathrm{XX}$, os esforços adotados pelas nações privilegiaram variáveis econômicas em detrimento de tantas outras como ambientais, políticas, culturais e sociais.

Esse modo de organização com privilégios econômicos para as elites - geralmente detentoras do poder - resultou em exclusão de grande parte da população. Nesse sentido, afirma-se que as relações capitalistas instrumentalizaram e racionalizaram as relações de pobreza e desigualdade, excluindo milhares de pessoas do acesso à educação.

Nesse cenário, incluem-se os Catadores e Catadoras de Materiais Reutilizáveis e Recicláveis (CMRR). Até 2010, parte desse grupo social tinha seus postos de trabalho em lixões localizados em todas as cidades do Brasil. Ali catavam materiais e alimentos para comer, vender e sobreviver. Muitos deles, após a regulamentação da norma, foram para as ruas, realizando a mesma tarefa, e poucos deles tiveram condições de se organizar em associações e cooperativas. Essa afirmação pode ser constatada pelos poucos associados das organizações e pelo grande número de "carrinheiros" que circulam pelas cidades. 
Os CMRR compõem uma rede territorial de catação e comercialização. Eles atuam de forma direta ou indireta para as administrações públicas, podem estar organizados em grupos ou não para a exercer a atividade e ficam dependentes da classificação dos materiais coletados, dos compradores de materiais e dos materiais que encontram nas lixeiras. São distintas as formas de trabalhar com os Resíduos Sólidos Recicláveis (RSR). Há aqueles que podem separar em suas casas e os que vendem o material como encontram nas ruas, gerando diferentes valores para os materiais.

Observando essas situações, o trabalho do catador pode ser entendido como um exemplo de desenvolvimento inclusivo no mercado informal de trabalho. As associações e cooperativas assumem protagonismo nos territórios com o advento da Lei Federal n 12.305, de 2010, que instituiu a Política Nacional dos Resíduos Sólidos Urbanos (PNRS).

A PNRS inclui o trabalho do catador e da catadora nas atividades da coleta seletiva, triagem, classificação, processamento e comercialização dos resíduos reutilizáveis e recicláveis desde que esses trabalhadores estejam organizados formalmente. Desse modo, a norma incentiva a criação e o desenvolvimento de associações e cooperativas. Todavia, as metas da PNRS são consideradas um desafio para as municipalidades, porque elas necessitam inserir na gestão compartilhada dos Resíduos Sólidos Urbanos (RSU) essas organizações. Quando organizados, os catadores devem ser contratados pelas prefeituras para realizar a separação e, por vezes, a coleta dos materiais recicláveis dispostos nas lixeiras das cidades.

Por pertencerem a uma classe social de baixa renda, esses trabalhadores ficam vulneráveis às instabilidades provenientes da atividade, possuem poucas oportunidades de capacitação e dependem dessa renda para sobreviver e sustentar suas famílias. Os conflitos e as contradições persistem porque, de um lado, os gestores, que são os responsáveis pela gestão dos RSU, atuam nos territórios atendendo interesses específicos e contrários à PNRS (DULLIUS; SILVA, 2018). Por outro, as associações ficam sujeitas às regras, as quais são instáveis e morosas. As relações entre eles são complexas, pois existem as eleições, os mandatos, as pressões políticas e o cotidiano dos trabalhadores alimentado por bolsas de auxílio, cestas básicas e outros (DULLIUS et al., 2019).

Os catadores e catadoras necessitam de ajuda do Ministério do Trabalho para auxiliar nas negociações com as prefeituras. Esse órgão procura garantir os direitos trabalhistas deles, na medida em que debatem com eles e recebem as reclamações dos dissensos e consensos das relações de poder jurídicas, econômicas e sociais. Não existe protagonismo nessa dinâmica territorial dos resíduos recicláveis e reutilizáveis (RAFFESTIN, 1993; SANTOS, 1999; HAESBAERT, 1999, 2004; SAQUET; SPOSITO, 2008). 
As condições instáveis de vida dos catadores foram avaliadas na PNRS, na medida em que instituiu a responsabilidade compartilhada dos geradores de resíduos e das associações, incorporando ações embasadas na sustentabilidade, Educação Ambiental (EA) e gerenciamento. Ela determina que os catadores sejam capacitados para partilhar as reponsabilidades sobre o ciclo de vida dos produtos, o que envolve a compreensão dos potenciais dos materiais recicláveis.

Nesse sentido, o presente artigo apresenta as dinâmicas territoriais de capacitação para catadores e catadoras estimuladoras de experiências inclusivas, reconhecimento e respeito. Corrobora com os preceitos da norma, pois trabalhou com os materiais encontrados na separação, os quais por vezes são descartados por falta de capacitação para transformá-los. Elas foram realizadas entre os anos de 2018 e 2019 na cidade de Matinhos-PR, com o auxílio dos preceitos da observação participante, pesquisa-ação e roda de conversa (FLICK, 2009). Os instrutores foram artesãos locais, professores e servidores públicos. Participaram e organizaram as oficinas os autores e discentes do Programa de Pós-Graduação em Tecnologia e Sociedade da Universidade Tecnológica Federal do Paraná (PPGTE - UTFPR).

\section{Metodologia}

Apoiados em Flick, (2009) a metodologia utilizada foi essencialmente de natureza qualitativa e exploratória, com uso de recursos da pesquisa participante e da pesquisa-ação. No contexto de Minayo (2010), a pesquisa é o caminho do pensamento, a prática exercida na abordagem da realidade. Para Flick (2009) a pesquisa qualitativa responde a questões muito particulares. Ela se dedica, nas Ciências Sociais, aos diferentes níveis de realidade que não podem ser quantificados. Existe um universo de significados que circula nas mentes das pessoas, cujas realidades podem ser vistas de diferentes ângulos. Conforme Flick (2009), na pesquisa qualitativa a observação também é um instrumento do qual o pesquisador pode se analisar e compreender detalhes particulares e específicos, explorar percepções visuais, auditivas, de tato e olfativas. Dentre as variáveis observáveis, estão as escolhas, aspirações, histórias de vida, crenças, valores e atitudes. As técnicas de coleta de dados e de compreensão do tema dos RSU aconteceram por meio de oficinas de capacitação, organizadas com materiais reutilizáveis e recicláveis. 


\section{Resultados e discussões}

Foi um desafio organizar e capacitar os CMRR organizados em associação na cidade de Matinhos-PR. As oficinas tiveram início em 2018, em função da necessidade de melhor compreender as relações entre a Prefeitura Municipal e as Associações responsáveis pela coleta, separação e comercialização dos materiais recicláveis. Nesse território, as dinâmicas de inserção dos catadores na coleta seletiva acontecem por meio de convênios e contratos, anuais, que necessitam serem reformulados e reapresentadas as documentações atualizadas, como a licença dos bombeiros, a licença ambiental e programa de controle médico e saúde ocupacional.

A primeira oficina de capacitação, intitulada "Dando vida a bonecas e bonecos", contemplou o reaproveitamento de retalhos de tecidos. Esse resíduo compõe mais de 15\% dos resíduos coletados pelas prefeituras no Brasil. Foi dada ênfase aos saberes que os participantes já tinham e acrescentouse o conjunto de conhecimentos interdisciplinares das áreas das Ciências Exatas (Aritmética e Matemática), da Linguística (vocabulário), de História (moda), de Ciências Naturais (meio ambiente) e Arte (moderna, contemporânea).

A oficina foi realizada na Associação dos Coletores e Selecionadores de Resíduos Sólidos de Matinhos (Ancresmat) e contou com a participação de associados. Também participaram da oficina os catadores e catadoras da Associação dos Agentes Ambientais de Matinhos (Amagem). A oficineira foi uma artesã do local.

Foram estimuladas as relações pessoais entre todos, sobretudo com a oficineira, para que as pessoas se sentissem abertas para partilhar e multiplicar os saberes e conhecimentos. Pode-se observar a diversidade de formas de apropriação e uso dos materiais recicláveis, bem como o desejo de construir algo pessoal para o lar e para a família. O ambiente da Associação permitiu transformar um local de separação de materiais em uma oficina de costura e arte. Os retalhos não foram vistos como lixo, e sim como um material novo, interessante, agradável de lidar e necessário para exercitar habilidades e descobrir talentos.

As dinâmicas criativas de aumentar o tempo de vida dos materiais descartados pelas pessoas na coleta seletiva revitalizaram valores e usos até então não imaginados. As ações se centraram em práticas que possibilitaram evitar o descarte imediato dos resíduos. A intenção foi prolongar a vida útil do material. Entre diferentes retalhos de tecidos, cores e formas geométricas, os bonecos começaram a aparecer e a ganhar vida (Figura 1). 


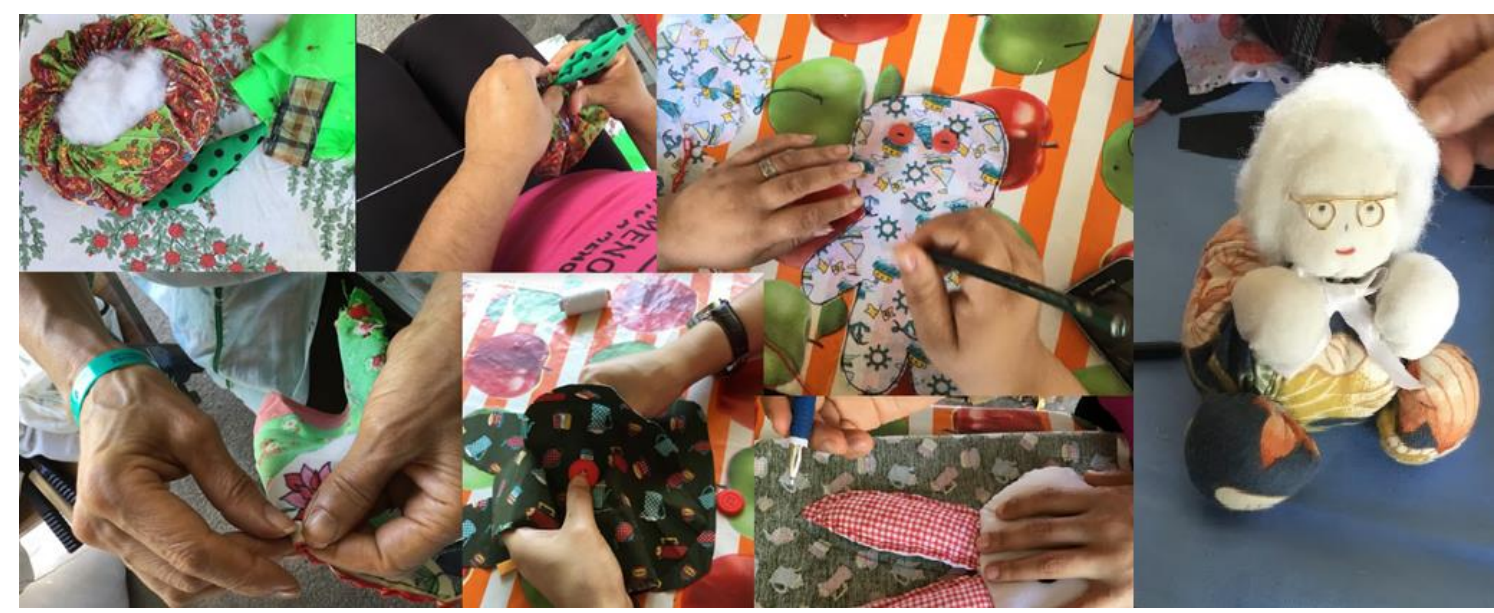

FONTE: Os autores (2018).

Nessa capacitação, observou-se a expansão das ideias, proatividade dos participantes, empenho, oportunidade de aprender e ensinar e o interesse pelos modos de preparar os alimentos que foram ofertados durante o café. Explorou-se a concepção do pertencimento ao local onde os catadores e catadoras dispõem seus materiais de separação, as mesas de comer e os espaços de circulação. Quando realizaram o trabalho praticaram e partilharam subjetividades e coletividades, hábitos, atitudes, valores, contradições, e ricas possibilidades de desconstrução e reconstrução. Do mesmo modo, essas intervenções culturais de concepção e de convivência trouxeram alternativas para a fragilidade das redes de apoio e recursos dos territórios para intervenção e inserção do trabalho do catador na PNRS.

As oficinas deram à Ancresmat um novo uso para o espaço de comer e trabalhar. O foco da atividade de separação foi desviado para a ampliação dos vínculos sociais. O simbólico pôde ser trabalhado, em especial nas escolhas feitas pelos participantes. Uma pessoa confeccionou um peixe porque seu neto admira esse animal, outra fez um cachorro para o seu bicho de estimação, outra escolheu a cabeça de um coelho e não quis fazer o corpo, outra que não conseguiu fazer a sua boneca sozinha e necessitou de atendimento individualizado da oficineira. Foi um momento de realização de atividades produtivas, expressão plástica e exercício coletivo de construção da cidadania. Destaca-se que ações para prolongar a vida dos materiais descartados oportunizaram reavivar talentos e ampliar momentos de recuperar hábitos terapêuticos, além de propiciar a possibilidade de ocupação do tempo livre com atividades artesanais. 


\section{Oficina para reaproveitamento de tecidos de guarda-chuva}

A oficina intitulada "Projeto guarda-chuva: almofadas, aventais e bolsas" também seguiu a linha do reaproveitamento de tecidos refugados e do trabalho em grupo. Os guarda-chuvas descartados possuem materiais recicláveis, como o ferro e o plástico. Porém, o tecido impermeável é descartado, desprivilegiando os conceitos de sustentabilidade econômica, ambiental e social.

No aspecto ambiental, os impactos ocorrem sobretudo pelo descarte inadequado e os diferentes materiais que compõem o objeto. No aspecto social, o guarda-chuva é utilizado por todos aqueles que se locomovem nos dias de chuva e não desejam ficar molhados, e nem ter seus pertences úmidos ou encharcados. No sentido econômico, os custos de confecção desse abrigo para intempéries variam conforme o modelo, a durabilidade e os materiais.

Em geral, os guarda-chuvas são objetos frágeis e funcionam por um tempo limitado devido ao uso de materiais e de mecanismos de baixa qualidade. É comum, nos dias de chuva, encontrar vários deles jogados pelas ruas, bancos e lixeiras. Em geral, eles são jogados nas calçadas e quando recolhidos pelo serviço de coleta são dispostos em aterros e lixões. Os coletados pelos caminhões da coleta seletiva são dirigidos para as associações de catadores de materiais recicláveis.

Para a oficina, foi necessário separar os tecidos da armação, lavá-los e guardá-los com segurança para posteriormente oferecer segurança no manuseio para os participantes. Foi uma catadora aposentada, em especial, que ajudou nessa operação, juntamente com os organizadores. Depois de lavados e guardados em uma caixa, eles foram levados para o local da oficina. Havia tecidos de cores e estampas diversas. As escolhas associaram-se com preferências e os interesses individuais. A oficineira convidada foi a mesma da oficina de bonecas. Ela preparou antecipadamente peças de amostra (almofada, avental e bolsas) que causaram surpresas e motivação para o trabalho.

A primeira ação de reaproveitamento foi a confecção da almofada, toda feita a mão. Com agulha e fio, todos fizeram um grande fuxico, sem necessitar cortar o tecido que cobre um guardachuva. O uso integral do pano não gerou retalhos. Depois de fechada a peça, ela recebeu a parte do enchimento. Havia um material reservado para esse fim, fruto de catação, que também foi higienizado. Foram enchimentos de cobertas e travesseiros. O acabamento foi feito com um botão grande, colocado no centro. Outras peças receberam adornos adicionais que estavam disponíveis ou que foram confeccionados, como por exemplo flores, folhas que foram encontrados no lixo.

A segunda peça exigiu o uso da máquina de costura e o corte dos tecidos. A oficineira trouxe duas máquinas e uma associada trouxe outra. Com as três máquinas de costura foi possível trabalhar coletivamente e produzir aventais, bolsas pequenas e porta-grampos. Os moldes foram feitos pela 
oficineira e copiados por alguns, que necessitaram bastante instrução para o correto corte e montagem. Esse tecido impermeável e resistente possibilitou a confecção de peças exclusivas que trouxeram prazer e comunhão de ideias (Figura 2).

As demais peças foram feitas individualmente. Cada pessoa imaginou um objeto que tinha necessidade de ter. Por exemplo, uma catadora queria um porta-grampos de roupa, ideal para armazenar grampos no momento de estender no varal as roupas para secar. Outra quis uma bolsa pequena para colocar objetos de higiene bucal. Esses artefatos necessitaram técnicas de costura mais elaboradas, com molde, medidas, corte e costura.

Os cabos de guarda-chuva não são materiais aceitos para reciclagem e, por isso, não agregam valor depois de usados. A maioria é feito de plástico duro, apresentando dificuldades para a comercialização. São termorrígidos, isto é, não derretem quando aquecidos, dificultando a reutilização. Um modo de prolongar a vida deles é transformá-los em um objeto útil. No caso, o filho de uma trabalhadora colaborou para a confecção de um cabideiro, feito com retalho de madeira (Figura 2).

FIGURA 2 - PRODUTOS DA OFICINA "PROJETO GUARDA-CHUVA: ALMOFADAS, AVENTAIS E BOLSAS"

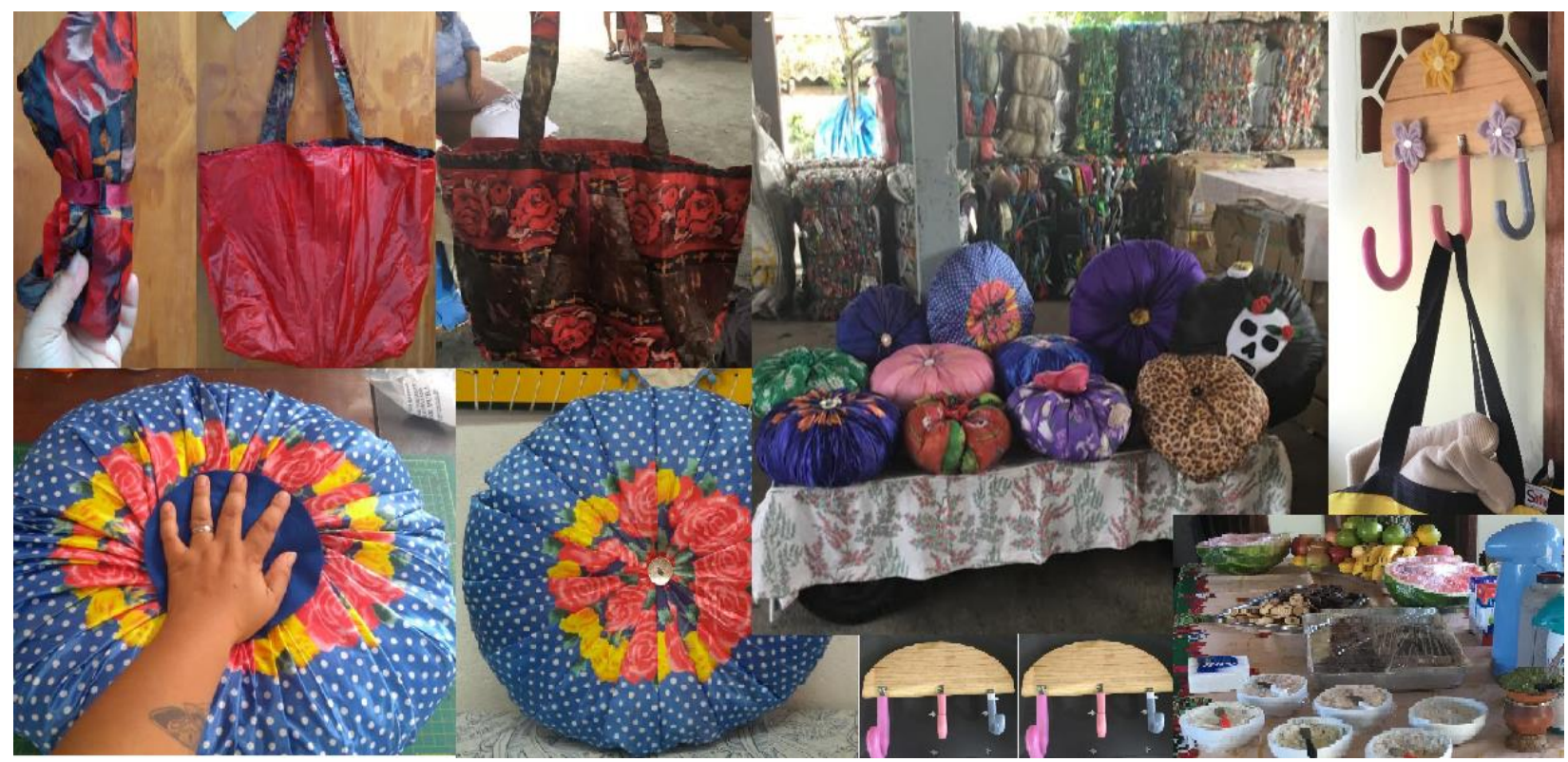

FONTE: Os autores (2019).

Outros elementos de sociabilidade que se destacaram na capacitação foram a participação de familiares, com histórias de vida reveladas durante a atividade. Arte, comida e conversa foram motivos de satisfação para todos. As peças foram admiradas e expostas para todos fotografarem. 


\section{Oficina para reaproveitamento de tecidos refugados na Amagem}

Havia um pedido dos catadoras e catadores associados à Associação de Materiais Recicláveis Amagem para a realização de uma oficina no espaço deles de separação. Desde o mês de março de 2019, eles aceitaram mudar a sede para um barracão da Prefeitura Municipal, que possui mais estrutura que o anterior onde eles estavam trabalhando. Não havia espaço físico adequado para armazenar os materiais, separar, enfardar e realizar oficinas.

O presidente da Amagem, motivado, colaborou e estimulou a efetivação da oficina intitulada "Brincando de torcer tecidos: a Abayomi". Foi uma ação inédita para os associados integrarem-se social e familiarmente e produzirem um objeto. A instrutora foi uma catadora-artesã, moradora da cidade de Matinhos-PR. Ela possui habilidades manuais e confecciona objetos artísticos desde pequena, tendo um espaço de exposição na Secretaria Municipal de Cultura, local onde outras artesãs do município comercializam suas peças. $\mathrm{O}$ artesanato com materiais encontrados nas lixeiras faz parte da sua vida. Ela sabe fazer uso também de outros materiais, como palhas, cipós, conchas e sementes.

Essa artesã iniciou a atividade contextualizando a boneca africana Abayomi, que é conhecida desde a época colonial, quando os colonizadores escravizaram pessoas para trabalhar nas terras brasileiras (1500-1800). Os portugueses capturavam pessoas na África para escravizá-las, levando-as para outros países em navios. As famílias viajavam em porões durante meses e as crianças ocupavam seu tempo brincando. Nas embarcações conhecidas como navios negreiros ${ }^{4}$, as mães rasgavam seus vestidos para fazer bonecas e bonecos.

A Abayomi era uma referência para os sonhos das crianças e um objeto para experenciar a coragem, a afetividade e o amor. A peça é feita com retalhos de tecidos refugados. Faz-se uma tira longa e em seguida se tecem os nós, formando a cabeça, as pernas, os pés e os braços. Primeiro se criou o corpo com a cabeça, dando um nó maior. Dois nós subsequentes, abaixo, fazem as pernas aparecer, e outros dois nós, com um pedaço pequeno de tecido, à parte, amarrado próximo à cabeça, representam os braços.

Sob a orientação da oficineira e conforme a disponibilidade de materiais, os participantes puderam fazer escolhas de cores e tecidos também para vestir as bonecas. Quando alguém confecciona uma peça para si, esta adquire mais significado simbólico e afetivo. Esses sentimentos declarativos foram identificados no fazer compartilhado, em espaço comum, por crianças e adultos. As bonecas e os bonecos foram atores no processo para reconfigurar experiências de ensinar e

\footnotetext{
${ }^{4}$ No poema épico "Navio Negreiro", de Castro Alves, concluído em 1868, em São Paulo, o autor denunciou as atrocidades feitas com os africanos na travessia do Oceano Atlântico.
} 
aprender, e de abertura ao mundo das ideias.

Eles se afastaram das ruas, onde trabalham dia e noite em busca do sustento, sem tempo para dedicar-se ao lazer e às atividades cognitivas. Estão excluídos do universo educacional, da experiência cultural de caminhar pelo bairro para sentir a natureza, ver o trânsito, as moradias, visitar lojas, fazer compras, passear e brincar. O espaço não existe independente do sujeito que nele está. Assim foi o caso da Abayomi, que começou a existir no espaço do barracão, espaço de abertura, inventivo e criativo. Aconteceram ligações com as informações, histórias e as culturas em uma performance diferente das usuais. No mínimo, cada um confeccionou duas peças, refinando, reconfigurando, reutilizando e diversificando os materiais. Sob o efeito da novidade, houve participantes que fizeram três, quatro, cinco e seis bonecas. A demonstração dos saberes e conhecimentos dos participantes ocorreu por meio da reprodução do ensinamento e mudança de comportamento. Foram abertas as portas para outros aprendizados. $\mathrm{Na}$ finalização da oficina, todas as peças foram colocadas sobre uma caixa de papelão para que fossem fotografadas (ver Figura 3).

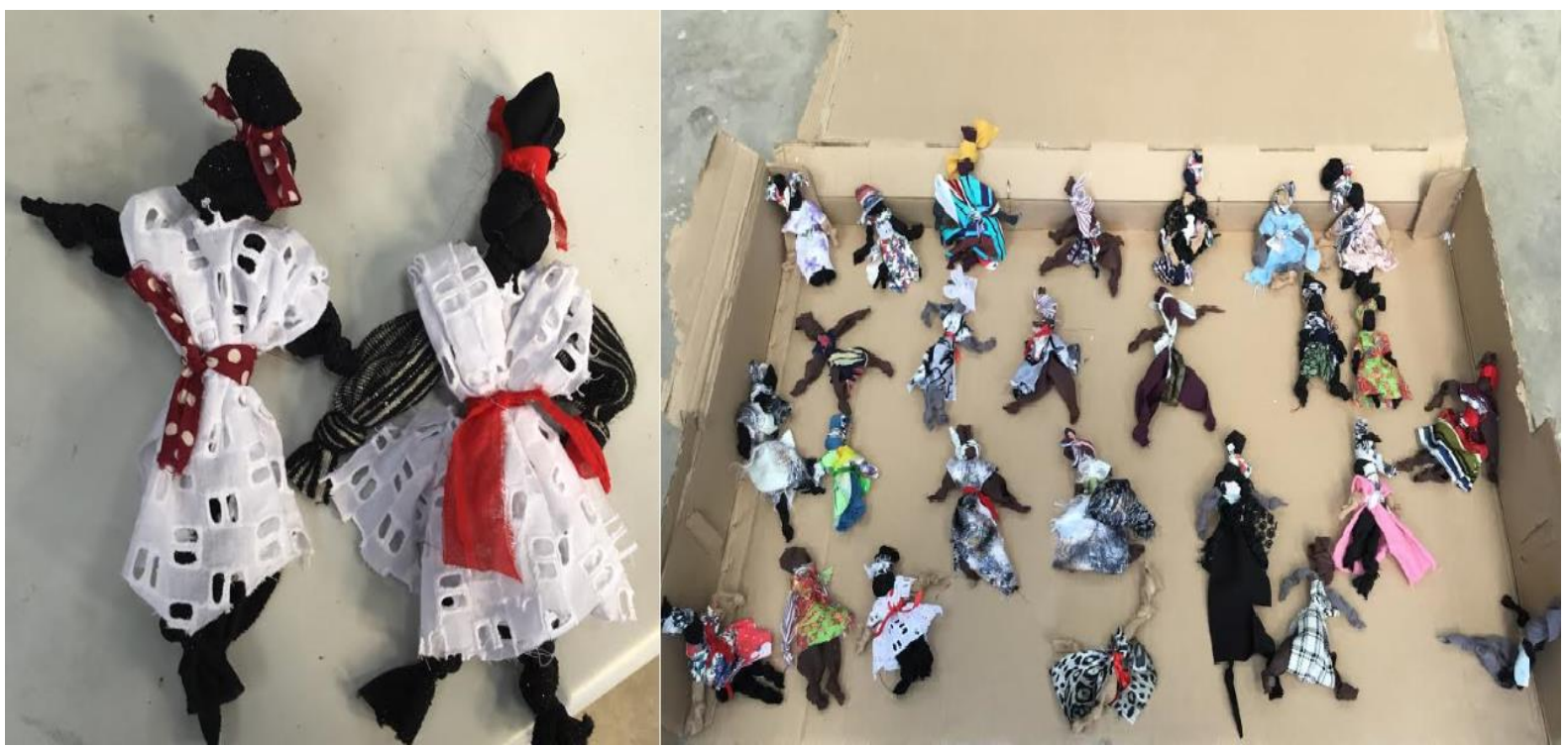

FONTE: Os autores (2019).

Oficina para reaproveitamento de tecidos refugados na Ancresmat: vasos para plantar

$\mathrm{Na}$ Ancresmat, que possui um espaço externo apropriado, com acesso à água e uma área livre, sem depósito de materiais, foi feita a oficina de reaproveitamento de tecidos refugados na confecção 
de vasos de cimento para plantio de Plantas Alimentícias Não Convencionais (PANCs). A ação, que visou à aplicação de saberes e conhecimentos, foi intitulada "Confecção de vasos de cimento com tecidos refugados", de modo a mostrar aos participantes mais uma forma de reaproveitamento de materiais. Ela foi realizada em duas etapas na Ancresmat, ou seja, foram necessários dois períodos do dia para que o objeto ficasse pronto. Uma terceira etapa ainda virá, quando será feito o acabamento.

A primeira delas correspondeu à produção de vasos, com o objetivo de plantar e adornar o espaço da Associação. Foi convidada para dirigir os trabalhos a doutoranda Marcia Regina Rodrigues da Silva Zago do PPGTE-UTFPR. A pesquisadora está desenvolvendo estudos sobre a vermicompostagem em escolas de ensino fundamental da rede municipal de Curitiba-PR de tempo integral, que necessitam de projetos para dar destino correto aos resíduos orgânicos. Paralelamente, ela está colaborando com as hortas escolares e divulgando o conhecimento sobre as PANCs, produzindo húmus e terra preta, na medida em que alimenta o minhocário com os resíduos produzidos nas escolas. Juntamente com a equipe de professores e professoras de nove escolas, a pesquisadora desenvolve o trabalho na linha da campanha da Prefeitura Municipal de Curitiba e da Secretaria Municipal de Educação "Comida de Verdade”.

Para incentivar também que, desde pequenos, os moradores da capital tenham consciência da importância da alimentação saudável, nove escolas municipais começam a receber sistemas de compostagem - denominados minhocários - que vão transformar resíduos orgânicos produzidos nas cozinhas das unidades em adubo para hortas dos locais. (CURITIBA, 2018).

Zago (2019) explica que o projeto da horta escolar permite aos alunos adquirir saberes interdisciplinares, que vão desde aqueles desenvolvidos pela biologia, passando por geografia, história, línguas, até os 17 Objetivos de Desenvolvimento Sustentável (ODS) (fome zero e agricultura sustentável, consumo e produção sustentáveis, saúde e bem-estar, educação de qualidade). Os ODS para 2030 fazem parte de um plano de ação para o planeta e seus habitantes, com 169 metas para o desenvolvimento sustentável nas dimensões econômica, social e ambiental.

As hortas também podem ser cultivadas em vasos e caixas, ocupando pouco espaço e apresentando bons rendimentos. São mais compactadas e permitem melhor observação das transformações pelas quais as plantas passam, bem como a aplicações de conceitos e facilitação da colheita. As metodologias para instalação e manutenção de hortas escolares são variadas, dependendo das plantas. As PANCs, por exemplo, são mais resistentes aos ataques de insetos e podem proteger hortaliças com folhas mais tenras. Todas essas ideias foram apresentadas para os catadores e catadoras durante as oficinas. Houve muitas trocas de saberes e experiências individuais, conhecimento dos 
usos de ervas medicinais, apontamento de locais ao redor da Associação onde se pode coletar mudas, dentre outras conversas sobre alimentos e saúde.

A pesquisadora definiu a confecção dos vasos como uma prática socioambiental e como o aprendizado de técnicas, dentre elas o preparo da massa, no qual se trabalha noções de ação e reação dos ingredientes, a água como solvente universal e a moldagem com materiais recicláveis. A massa poderia ser usada também para o fabrico de potes, tigelas e bacias, mas o peso da massa dificulta o movimento e deslocamento das peças e a possibilidade de elas quebrarem ou racharem inviabiliza o seu uso para determinados fins. Outro fator que pode prejudicar a peça é a qualidade da massa, que precisa estar amolecida para auferir a forma de vaso.

O processo de formação dos vasos aconteceu na primeira etapa da oficina sobre uma lona plástica. Depois de prontos, eles ficaram no local para secar, na sombra, no sol, no vento e na chuva durante 20 dias para adquirir resistência. O período de descanso dos vasos para transformá-lo em um objeto útil foi favorável, com clima seco e ensolarado.

Na segunda etapa, após o processo de secagem e repouso, eles foram retirados dos moldes e analisados sob o ponto de vista das falhas e defeitos das peças e dos materiais. Por exemplo, os tecidos molhados na massa de cimento foram de diversos tipos, de algodão, nylon, malha e sarja e apresentaram secagens diferenciadas. Sua aparência mudou e houve necessidade de reforçar as bordas, acentuar os furos para escorrer a água e cobrir estruturas. Os vasos que não secaram bem e os remodelados ficaram em repouso para obterem fortaleza e consistência. Os demais foram colocados nos devidos lugares para receber as plantas. Um foi colocado no portão de entrada e outro na parte coberta. Os outros ficaram no pequeno jardim ao lado das mesas de separação. O objetivo foi colocálos em pontos estratégicos para serem vistos e cuidados. Eles se tornaram utensílios para acomodar plantas nativas, PANCs, flores, hortaliças e plantas em geral.

Na Figura 4, vê-se o processo de confecção de um dos vasos e plantio. Ficou faltando a terceira etapa, que será a pintura dos vasos. A massa, que atendeu às expectativas de dureza e rigidez, foi feita por um catador que trabalhou 30 anos na construção civil. As formas geométricas e os volumes das peças variaram bastante e por isso foram escolhidas espécies para plantio de acordo com seu potencial de crescimento em altura e profundidade, de acordo com o tamanho do vaso. Foi um excelente momento para valorizar e adornar o local de trabalho e o ambiente natural da vegetação remanescente da Mata Atlântica. 
FIGURA 4 - ATIVIDADES DE CONFECÇÃO DE VASOS E PLANTIO DE PANCS E OUTRAS ESPÉCIES

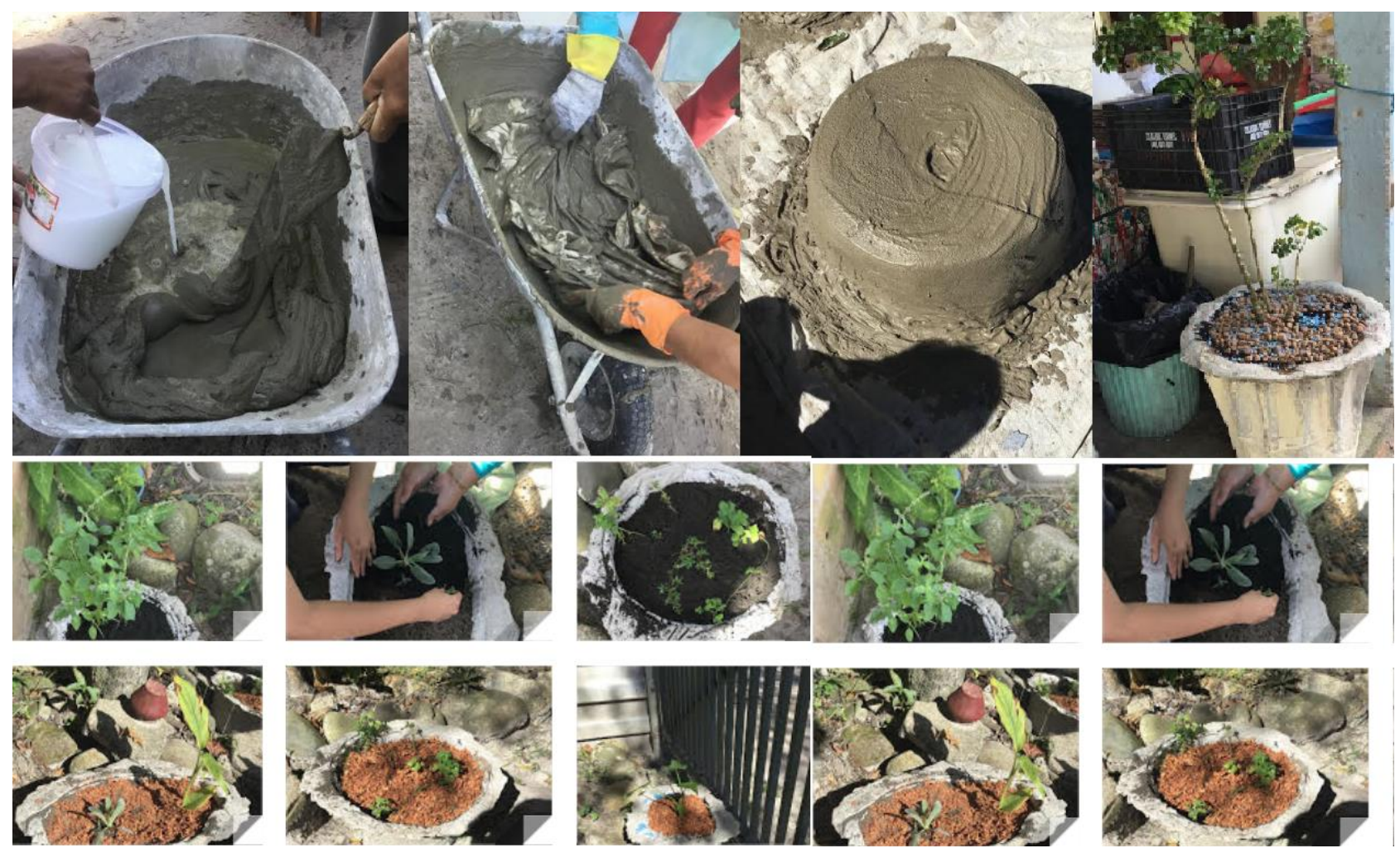

FONTE: O autor (2019).

\section{Considerações finais}

A produção de resíduos sólidos urbanos é uma realidade para todas as cidades do mundo. $\mathrm{O}$ consumo de bens e serviços cresceu juntamente com as populações e a apropriação de espaços. Os processos de degradação dos materiais, que são diversificados, tornaram-se complexos, sobretudo porque as matérias orgânicas se misturam aos plásticos, metais e vidros. Grande parte dos resíduos gerados vem da confecção de roupas e acessórios necessários à humanidade para se proteger das intempéries.

Como fazer a gestão do descarte e da produção de resíduos nas cidades? No Brasil, foram criados mecanismos como a PNRS, a reciclagem, a criação de aterros sanitários, a coleta seletiva, a compostagem e a vermicompostagem, as leis de controle da poluição do meio ambiente, dentre outros.

A geração, acondicionamento, armazenamento, coleta, transporte, tratamento e destinação final dos resíduos sólidos faz parte das dinâmicas territoriais dos municípios. Nesse contexto, estão 
as associaçoes dos catadores de materiais recicláveis, como é o caso da Ancresmat e Amagem da cidade de Matinhos-PR.

Elas recebem diariamente tecidos refugados, que são enviados para o aterro por não haver indústrias de reciclagem próximas aos locais de geração. As oficinas de capacitação foram realizadas para dar nova utilidade para resíduos não reprocessados. Além de terem sido atividades artesanais de incremento sociocultural e político, de reconhecimento e respeito, elas possibilitaram multiplicar saberes e técnicas de reaproveitamento de materiais recicláveis. Ressalta-se a importância de a sociedade separar adequadamente os resíduos, ação singular e fundamental para cumprir os ODS, seguir o caminho do desenvolvimento sustentável e permitir maiores rendas e empoderamento para as classes desfavorecidas que trabalham com os materiais recicláveis.

\section{Agradecimentos}

As oficinas foram dinâmicas territoriais que contaram com a participação de pessoas, espaços e lugares no território de Matinhos-PR, em prol do meio ambiente, com o apoio de: Instituto Federal do Paraná, campus Paranaguá; do PPGTE-UTFPR; da oficineira Daiane Cristina Werf Weiss Diatchuk, artesã do município de Matinhos e estudante da UFPR Setor Litoral; da catadora e artesã Jolcineide Martins da Rosa, estudante de graduação da UFPR Setor Litoral, da Michele Cristina Dullius, Técnica em Enfermagem e estudante de graduação da UFPR Setor Litoral; e, em especial, dos catadores e catadoras das Associações Amagem e Ancresmat.

\section{Referências}

BRASIL. Lei Federal 12.305, de 2 de agosto de 2010. Política Nacional de Resíduos Sólidos. Diário Oficial da União. República Federativa do Brasil, Brasília, DF, 3 ago. 2010. Disponível em: http://www.planalto.gov.br/ccivil_03/_ato2007-2010/2010/lei/112305.htm. Acesso em: 25 ago. 2017.

CURITIBA. Notícias. Comida de verdade. Campanha incentiva curitibanos a adotar práticas saudáveis de alimentação. 2018. Disponível em: https://www.curitiba.pr.gov.br/noticias/campanhaincentiva-curitibanos-a-adotar-praticas-saudaveis-de-alimentacao/47969. Acesso em: 28 nov. 2019.

DULliUS, A.; SILVA, M. C.; DIAS, M. S. L. (2017). Coleta e disposição de resíduos sólidos na cidade de Matinhos-PR. In: II Simpósio Brasileiro de Desenvolvimento Territorial Sustentável (II 
SBDTS), 2017, Matinhos. ANAIS DO II Simpósio Brasileiro de Desenvolvimento Territorial Sustentável (II SBDTS). Matinhos: Universidade Federal do Paraná. v. 1. p. 1482-1491.

DULliUS, A.; SILVA, M. C. A região do lagamar: fronteiras abertas para o re/ordenamento territorial. Revista Eletrônica Expedições: Teoria da História e Historiografia, v. 7, p. 84-97, 2017.

FLICK, Uwe. Introdução à pesquisa qualitativa. 3. ed. Porto Alegre: Artmed, 2009.

LEME, A. A. Desenvolvimento e Sociologia: uma aproximação necessária. Sociedade e Estado, Brasília, v. 30, n. 2, p. 495-527, 2015.

MINAYO, Maria Cecília de Souza (Org.). Pesquisa social: teoria, método e criatividade. 29. ed. Petrópolis, RJ: Vozes, 2010. (Coleção temas sociais)

RAFFESTIN, C. Por uma geografia do poder. São Paulo: Ática, 1993.

SACHS, Ignacy. Desenvolvimento includente, sustentável, sustentado. Rio de Janeiro: Garamond, 2004.

SANTOS, M. O dinheiro e o território. Rev. Geographia, ano 1, n. 1, 1999.

SAQUET. M. A.; ESPOSITO, E. S. Território, territorialidade e desenvolvimento: diferentes perspectivas em nível nacional e no Brasil. In: ALVES, A. F; CANDIOTTO, L. Z. P; CARRIJO, B. R. Desenvolvimento territorial e agroecologia. São Paulo: Expressão Popular, 2008.

VIEIRA, P. H. F. Rumo ao desenvolvimento territorial sustentável: esboço de roteiro metodológico participativo. Revista Eisforia (4). Florianópolis: UFSC, 2003.

ZAGO, M. R. R. S. Entrevista concedida ao pesquisador Alexandre Dullius. Curitiba, 2019.

Artigo recebido em 29/11/2019. Aceito para publicação em 17/12/2019. 